\title{
PENELITIAN AIR BERSIH DI PT. SUMMIT PLAST CIKARANG
}

\author{
Maria Christine Sutandi \\ Jurusan Teknik Sipil - Universitas Kristen Maranatha \\ Email: mrxtine@gmail.com
}

\begin{abstract}
ABSTRAK
Air merupakan kebutuhan dasar dan sangatlah penting bagi manusia, karena manusia tidak dapat bertahan hidup tanpa air, terutama sebagai air minum, disamping sebagai mandi, cuci, dan kakus. Kebutuhan akan air bersih mengalami peningkatan kurang lebih $1 \%$ setiap tahunnya seiring dengan meningkatnya populasi manusia sebesar $2 \%$ pertahun. Dengan meningkatnya populasi manusia yang pada umumnya diiringi juga dengan modernisasi serta menurunnya lingkungan hidup, maka kebutuhan akan air bersih sangatlah penting, karena air bersih ini berperan cukup besar dalam kesehatan. Dalam hal ini air yang sering dipakai oleh manusia adalah air permukaan, sehingga dapat dipastikan air yang akan ditinjau adalah air permukaan, jikalau air permukaan ini mengalami penurunan kwalitas akibat ulah manusia sendiri, maka dapatlah dipastikan kesehatan pastilah menurun. Untuk itulah disarankan untuk ditelaah lebih mendalam air yang ada disekitar lokasi yang akan dibuat perindustrian ini, agar tidak merusak lingkungan dan masyarakat juga tidak mengalami gangguan kesehatan.
\end{abstract}

Kata Kunci : Air Bersih.

\section{PENDAHULUAN}

\section{Latar Belakang}

Air merupakan kebutuhan dasar dan sangatlah penting bagi manusia, karena manusia tidak dapat bertahan hidup tanpa air, terutama sebagai air minum. Ketersedian air di dunia ini tidak pernah berkurang, bahkan dapat dikatakan berlimpah, tetapi yang dapat dikonsumsi oleh manusia hanya sekitar 5 \% saja, sedangkan dengan tingginya tingkat modernisasi menyebabkan menurunnya kualitas air yang $5 \%$ tadi sehingga makin sedikitlah jumlah air yang dapat dikonsumsi. Setiap tahun kondisi lingkungan hidup cenderung menurun. Selain krisis air, negeri ini juga menjadi langganan bencana alam. Untuk menghindari adanya kerusakan lingkungan maka diadakan penelitian air pada lokasi setempat. Apakah air tanah lokasi ini bersih.

Selain hal diatas, tingkat populasi manusiapun bertambah sekitar $2 \%$, sehingga makin besar pula tingkat kebutuhan akan air bersih ini. Kondisi ini akan bertambah parah ditahun 2025, dikarenakan 1,8 miliar manusia akan tinggal di kawasan yang mengalami kelangkaan air secara absolut. Akibat kalangkaan air bersih ini pastilah berdampak negatif terutama dibidang kesehatan.

Sistem penyediaan air bersih di daerah perkotaan dianjurkan diperbanyak, tetapi hal demikian sangatlah banyak kendalanya, antara lain cakupan pelayanan yang rendah, tingkat pendidikan masyarakat yang rendah pula dan yang terutama kepedulian masyarakat akan kebersihan lingkungan yang semakin hari semakin tidak peduli. 
Sehingga dalam hal ini diperlukan adanya observasi terhadap sarana dan prasarana yang telah ada selain membangun kepedulian masyarahat sekitar tempat tinggalnya akan kebersihan lingkungan.

Air bersih disini didefinisikan sebagai air yang memenuhi persyaratan kesehatan, baik itu untuk minum, mandi, cuci dan lain sebagainya. Air yang bersih sangat dibutuhkan bagi kehidupan manusia.

Air dikatakan Bersih bila :

1. Terlihat jernih

2. Tidak berbau

3. Tidak mempunyai rasa

Adapun dibangunnya sarana air bersih antara lain adalah untuk meningkatkan kesehatan masyarakat, kesehatan lingkungan, meningkatkan effisiensi waktu dan effektifitas pemanfaatan air bersih. Dalam hal disini sumber air bersih yang dapat dimanfaatkan adalah air tanah. Sedangkan air tanah yang boleh dipakai adalah air permukaan. Air tanah pada lokasi ini antara kedalaman 10 - $14 \mathrm{~m}$

Air tanah ini akan diambil dengan cara digali yang diberi pompa, apakah itu jenis dari pompa mesin maupun pompa tangan atau di timba, karena hal demikian termudah dan aman serta yang terpenting adalah tidak merusak lingkungan sekitar.

\section{Tujuan Penelitian}

Mempelajari air tanah permukaan, sehingga dapat dijadikan air bersih.

\section{Ruang Lingkup}

- Air permukaan kedalaman $10 \mathrm{~m}-14 \mathrm{~m}$.

- Penelitian dilakukan dengan mengambil sampel pada lokasi dan lokasi sekitar, yaitu pada PT.Summit Plast, Cikarang. 


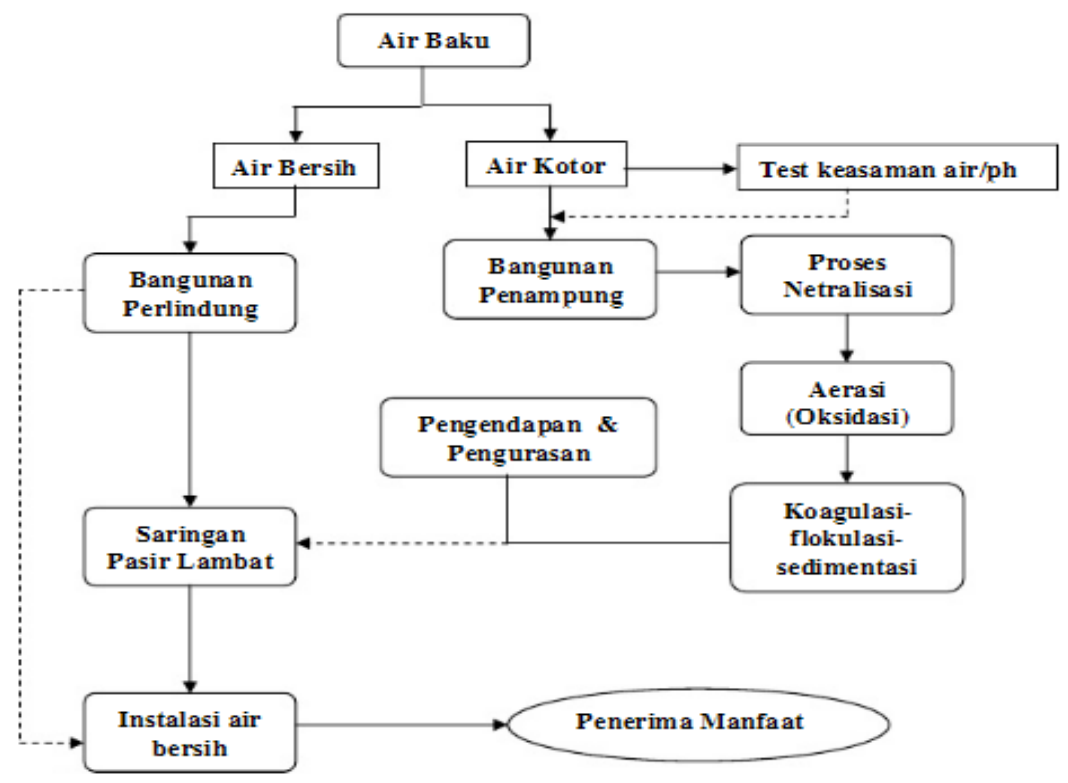

Gambar 1. Bagan Pengolahan Air Baku.

Air yang diambil pada awalnya akan ditampung pada tempat penampungan yang memenuhi syarat - syarat tertentu, antara lain sebagai pelepas tekanan, tempat pegendapan, dinding tidak bersudut dengan tujuan mudah untuk dibersihkan, di bagian atas mempunyai lubang yntuk orang masuk guna perbaikkan maupun pembersihan dll.

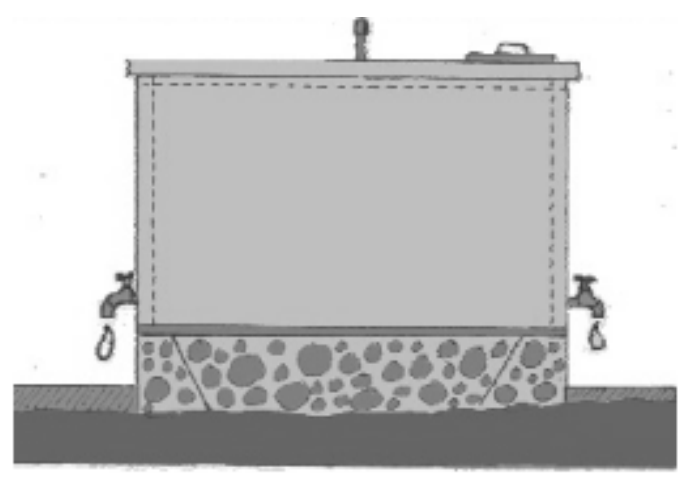

Gambar 2. Contoh Bak Penampungan sederhana.

\section{TINJAUAN LITERATUR}

Berdasarkan UU RI No.7 Tahun 2004 dan Keputusan Mentri Kesehatan Nomor 907 Tahun 2002, disebutkan beberapa pengertian terkait dengan air, yaitu Sumber Daya Air adalah air dengan daya air yang ada di dalamnya. Air adalah segala jenis air yang ada di sekitar bumi ini termasuk yang ada di dalamnya. 
Sedangkan Air Bersih adalah air yang digunakan untuk keperluan sehari-hari yang memenuhi syarat tertentu, seperti tidak berbau, tidak mempunyai rasa dan terlihat jernih. Air Bersih ini dapat terlihat di permukaan tanah, didalam tanah serta di udara.

Dengan kepadatan penduduk yang semakin meningkat, tingkat kesadaran akan kebersihan lingkungan yang menurun serta tingginya eksploitasi sumber air, hal demikian sangatlah berpengaruh terhadap kwalitas air.

Pemerintah mengeluarkan Kepmenkes No 907/Menkes/SK/VII/2002 tentang syarat dan pengawasan Kwalitas Air, antara lain bebas dari bahan-bahan anorganik dan organik serta bebas dari zat-zat kimia berbahaya.

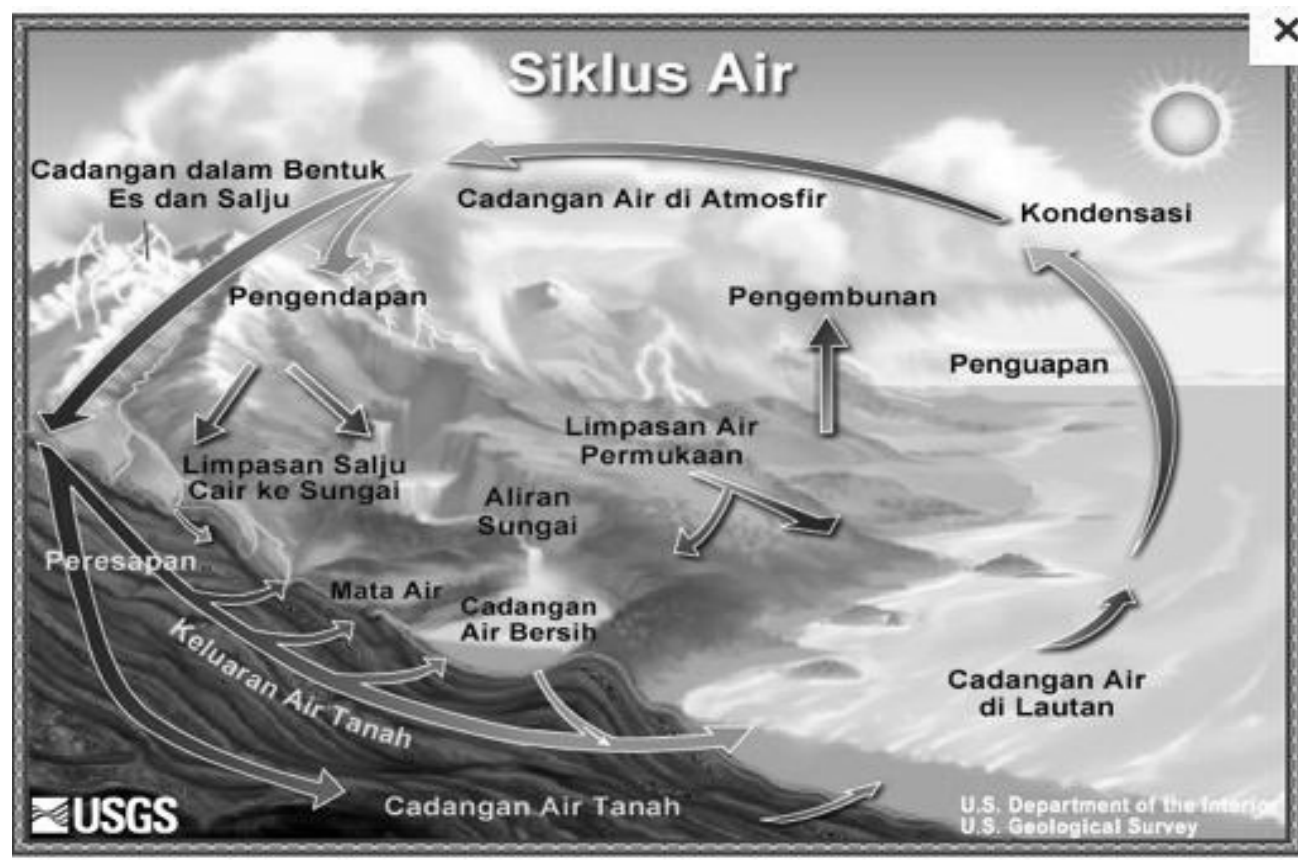

Gambar 3. Siklus Air [http:// Google.com/search/siklus air].

Air merupakan zat cair yang dinamis bergerak dan mengalir melalui siklus hidrologi yang abadi. Siklus tersebut adalah pertama, penguapan dari laut ke udara sebanyak $502.800 \mathrm{~km} 3$ dan penguapan dari daratan sebanyak $74.200 \mathrm{~km} 3$ per tahun. Kemudian kedua, curah hujan (yang berasal dari penguapan air dari laut dan darat , yang jatuh ke laut sebanyak 458.000 km3 dan ke daratan 119.000 km3 per tahun. Ketiga, air daratan berjumlah $44.800 \mathrm{~km} 3$ terbagi menjadi $42.700 \mathrm{~km} 3$ mengalir di permukaan tanah dan 2,100 km3 mengalir di dalam tanah selanjutnya semua berkumpul di laut. 


\section{HASIL PENELITIAN DAN PEMBAHASAN}

Tabel 1. Hasil penelitian 1.

\begin{tabular}{|c|c|c|c|c|c|c|c|}
\hline \multirow{2}{*}{ No } & \multirow{2}{*}{ Parameter } & \multirow{2}{*}{ Satuan } & \multirow{2}{*}{$\begin{array}{c}\text { Batas max } \\
\text { air bersih }\end{array}$} & \multicolumn{4}{|c|}{ Hasil Penelitian } \\
\hline & & & & $\mathrm{A}$ & $\mathrm{B}$ & $\mathrm{C}$ & $\mathrm{D}$ \\
\hline & FISIKA & & & & & & \\
\hline 1 & Warna & TCU & 50 & 18 & 2 & 1 & 3 \\
\hline 2 & Rasa & - & $\mathrm{x}$ & $\mathrm{x}$ & $\mathrm{x}$ & $\mathrm{x}$ & $\mathrm{x}$ \\
\hline 3 & Bau & - & $\mathrm{x}$ & $\mathrm{x}$ & $\mathrm{x}$ & $\mathrm{x}$ & $\mathrm{x}$ \\
\hline 4 & Kekeruhan & NTU & 25 & 2.7 & 0 & 0 & 2.9 \\
\hline \multirow[t]{2}{*}{5} & Konduktivity & Ms & - & 80 & 99 & 205 & 578 \\
\hline & KIMIA & & & & & & \\
\hline 6 & $\mathrm{pH}$ & $\mathrm{mg} / \mathrm{L}$ & $6.5-9.0$ & 7.27 & 5.24 & 4.48 & 6.65 \\
\hline 7 & Besi & $\mathrm{mg} / \mathrm{L}$ & 1 & 0.38 & 0.03 & 0.04 & 0.03 \\
\hline 8 & Kalsium & $\mathrm{mg} / \mathrm{L}$ & 200 & 12.15 & 151 & 29 & 45 \\
\hline 9 & Kholida & $\mathrm{mg} / \mathrm{L}$ & 600 & 5.3 & 7.7 & 15 & 17 \\
\hline 10 & Kesadahan & $\mathrm{mg} / \mathrm{L}$ & 500 & 49.55 & 456.88 & 103.88 & 105.91 \\
\hline 11 & Magnesium & $\mathrm{mg} / \mathrm{L}$ & 150 & 4.38 & 18.6 & 11.1 & 7.3 \\
\hline 12 & Mangan & $\mathrm{mg} / \mathrm{L}$ & 0.5 & 0.28 & 9.44 & 13.29 & 1.81 \\
\hline 13 & Nitrat & $\mathrm{mg} / \mathrm{L}$ & 50 & 16.8 & 5.9 & 10.2 & 19.6 \\
\hline 14 & Nitrit & $\mathrm{mg} / \mathrm{L}$ & 3 & 0.578 & 0.041 & 0.237 & 0.389 \\
\hline 15 & Sulfat & $\mathrm{mg} / \mathrm{L}$ & 400 & 7.5 & 348.49 & 121.67 & 75.93 \\
\hline 16 & Zat Padat Terlarut & $\mathrm{mg} / \mathrm{L}$ & 1500 & 62 & 734 & 250 & 381 \\
\hline 17 & Zat Organik & $\mathrm{mg} / \mathrm{L}$ & - & 8.1 & 2.3 & 1.9 & 0.2 \\
\hline 18 & Timbal & $\mathrm{mg} / \mathrm{L}$ & 0.05 & 0.02 & 0.67 & 0.18 & 0.001 \\
\hline \multirow[t]{2}{*}{19} & Kronium & $\mathrm{mg} / \mathrm{L}$ & 0.05 & 0 & 0.03 & 0.02 & 0 \\
\hline & BIOLOGI & & & & & & \\
\hline 20 & Bakteri Coliform & & - & - & - & - & - \\
\hline
\end{tabular}

Tabel 2. Hasil penelitian 2.

\begin{tabular}{|r|l|c|c|c|c|c|c|}
\hline \multirow{2}{*}{ No } & \multirow{2}{*}{ Parameter } & \multirow{2}{*}{ Satuan } & \multirow{2}{*}{$\begin{array}{c}\text { Batas max } \\
\text { air bersih }\end{array}$} & \multicolumn{5}{c|}{ Hasil Penelitian } \\
\cline { 6 - 8 } & & & & & $\mathrm{F}$ & $\mathrm{G}$ & $\mathrm{H}$ \\
\hline & FISIKA & & & & & \\
\hline 1 & Warna & $\mathrm{TCU}$ & 50 & 28 & 13 & 32 & 5 \\
\hline 2 & Rasa & - & $\mathrm{x}$ & $\mathrm{x}$ & $\mathrm{x}$ & $\mathrm{x}$ & $\mathrm{x}$ \\
\hline 3 & Bau & - & $\mathrm{x}$ & $\mathrm{x}$ & $\mathrm{x}$ & $\mathrm{x}$ & $\mathrm{x}$ \\
\hline 4 & Kekeruhan & $\mathrm{NTU}$ & 25 & 2.7 & 0 & 0 & 2.9 \\
\hline 5 & Konduktivity & $\mathrm{Ms}$ & - & 75 & 79 & 105 & 58 \\
\hline & KIMIA & & & & & & \\
\hline 6 & pH & $\mathrm{mg} / \mathrm{L}$ & $6.5-9.0$ & 8.27 & 7.24 & 4.68 & 4.65 \\
\hline 7 & Besi & $\mathrm{mg} / \mathrm{L}$ & 1 & 0.93 & 0.83 & 0.94 & 0.88 \\
\hline 8 & Kalsium & $\mathrm{mg} / \mathrm{L}$ & 200 & 212.15 & 151 & 229 & 145 \\
\hline 9 & Kholida & $\mathrm{mg} / \mathrm{L}$ & 600 & 9.8 & 4.9 & 21 & 11 \\
\hline 10 & Kesadahan & $\mathrm{mg} / \mathrm{L}$ & 500 & 39.55 & 46.81 & 103.88 & 105.98 \\
\hline 11 & Magnesium & $\mathrm{mg} / \mathrm{L}$ & 150 & 7.3 & 9.44 & 10.2 & 14.1 \\
\hline 12 & Mangan & $\mathrm{mg} / \mathrm{L}$ & 0.5 & 0.88 & 9.14 & 13.21 & 1.41 \\
\hline 13 & Nitrat & $\mathrm{mg} / \mathrm{L}$ & 50 & 7.27 & 8.4 & 4.48 & 5.62 \\
\hline 14 & Nitrit & $\mathrm{mg} / \mathrm{L}$ & 3 & 0.99 & 0.11 & 0.13 & 0.74 \\
\hline 15 & Sulfat & $\mathrm{mg} / \mathrm{L}$ & 400 & 7.5 & 48.49 & 11.67 & 75.93 \\
\hline 16 & Zat Padat Terlarut & $\mathrm{mg} / \mathrm{L}$ & 1500 & 162 & 334 & 259 & 138 \\
\hline 17 & Zat Organik & $\mathrm{mg} / \mathrm{L}$ & - & - & - & 0.04 & 0.02 \\
\hline 18 & Timbal & $\mathrm{mg} / \mathrm{L}$ & 0.05 & 0.02 & 0.07 & 0.108 & 0.001 \\
\hline 19 & Kronium & $\mathrm{mg} / \mathrm{L}$ & 0.05 & 0.03 & - & - & 0.012 \\
\hline & BIOLOGI & & & & & & \\
\hline 20 & Bakteri Coliform & & - & - & - & - & - \\
\hline
\end{tabular}


Tabel 3. Hasil penelitian 3.

\begin{tabular}{|r|l|c|c|c|c|c|c|}
\hline \multirow{2}{*}{ No } & \multirow{2}{*}{ Parameter } & \multirow{2}{*}{ Satuan } & \multirow{2}{*}{$\begin{array}{c}\text { Batas max air } \\
\text { bersih }\end{array}$} & \multicolumn{5}{c|}{ Hasil Penelitian } \\
\cline { 6 - 8 } & & & & & $\mathrm{J}$ & $\mathrm{K}$ & $\mathrm{L}$ \\
\hline & FISIKA & & & & & \\
\hline 1 & Warna & $\mathrm{TCU}$ & 50 & 18 & 22 & 12 & 8 \\
\hline 2 & Rasa & - & $\mathrm{x}$ & $\mathrm{x}$ & $\mathrm{x}$ & $\mathrm{X}$ & $\mathrm{x}$ \\
\hline 3 & Bau & - & $\mathrm{x}$ & $\mathrm{x}$ & $\mathrm{x}$ & $\mathrm{x}$ & $\mathrm{x}$ \\
\hline 4 & Kekeruhan & $\mathrm{NTU}$ & 25 & 2.7 & 0 & 0 & 2.9 \\
\hline 5 & Konduktivity & $\mathrm{Ms}$ & - & 89 & 99 & 225 & 277 \\
\hline & KIMIA & & & & & & \\
\hline 6 & pH & $\mathrm{mg} / \mathrm{L}$ & $6.5-9.0$ & 7.27 & 8.4 & 4.48 & 5.62 \\
\hline 7 & Besi & $\mathrm{mg} / \mathrm{L}$ & 1 & 1.30 & 1.13 & 1.0 & 0.95 \\
\hline 8 & Kalsium & $\mathrm{mg} / \mathrm{L}$ & 200 & 12.55 & 133 & 29 & 55 \\
\hline 9 & Kholida & $\mathrm{mg} / \mathrm{L}$ & 600 & 5.3 & 5.7 & 18 & 15 \\
\hline 10 & Kesadahan & $\mathrm{mg} / \mathrm{L}$ & 500 & 29.51 & 66.18 & 43.88 & 55.11 \\
\hline 11 & Magnesium & $\mathrm{mg} / \mathrm{L}$ & 150 & 4.82 & 18.1 & 31.5 & 7.32 \\
\hline 12 & Mangan & $\mathrm{mg} / \mathrm{L}$ & 0.5 & 14.7 & 9.44 & 13.11 & 4.78 \\
\hline 13 & Nitrat & $\mathrm{mg} / \mathrm{L}$ & 50 & 3.3 & 2.9 & 14.2 & 13.1 \\
\hline 14 & Nitrit & $\mathrm{mg} / \mathrm{L}$ & 3 & 0.237 & 0.389 & 0.051 & 0.117 \\
\hline 15 & Sulfat & $\mathrm{mg} / \mathrm{L}$ & 400 & 62 & 134 & 150 & 181 \\
\hline 16 & Zat Padat Terlarut & $\mathrm{mg} / \mathrm{L}$ & 1500 & 233 & 338 & 277 & 189 \\
\hline 17 & Zat Organik & $\mathrm{mg} / \mathrm{L}$ & - & 1.1 & - & 0.09 & 0.21 \\
\hline 18 & Timbal & $\mathrm{mg} / \mathrm{L}$ & 0.05 & 0.021 & 0.07 & 0.03 & 0.001 \\
\hline 19 & Kronium & $\mathrm{mg} / \mathrm{L}$ & 0.05 & 0.01 & - & 0.01 & 0.031 \\
\hline & BIOLOGI & & & & & & \\
\hline 20 & Bakteri Coliform & & - & - & - & - & - \\
\hline
\end{tabular}

Tabel 4. Hasil penelitian 4.

\begin{tabular}{|r|l|c|c|c|c|c|c|}
\hline \multirow{2}{*}{ No } & \multirow{2}{*}{ Parameter } & \multirow{2}{*}{ Satuan } & \multirow{2}{*}{$\begin{array}{c}\text { Batas max } \\
\text { air bersih }\end{array}$} & \multicolumn{5}{|c|}{ Hasil Penelitian } \\
\cline { 6 - 8 } & & & & $\mathrm{M}$ & $\mathrm{N}$ & $\mathrm{O}$ & $\mathrm{P}$ \\
\hline & FISIKA & & & & & \\
\hline 1 & Warna & $\mathrm{TCU}$ & 50 & 8 & 11 & 14 & 10 \\
\hline 2 & Rasa & - & $\mathrm{x}$ & $\mathrm{x}$ & $\mathrm{x}$ & $\mathrm{x}$ & $\mathrm{x}$ \\
\hline 3 & Bau & - & $\mathrm{x}$ & $\mathrm{x}$ & $\mathrm{x}$ & $\mathrm{x}$ & $\mathrm{x}$ \\
\hline 4 & Kekeruhan & $\mathrm{NTU}$ & 25 & 2.7 & 0 & 0 & 2.9 \\
\hline 5 & Konduktivity & $\mathrm{Ms}$ & - & 180 & 199 & 205 & 468 \\
\hline & KIMIA & & & & & & \\
\hline 6 & pH & $\mathrm{mg} / \mathrm{L}$ & $6.5-9.0$ & 7.29 & 7.27 & 5.47 & 5.15 \\
\hline 7 & Besi & $\mathrm{mg} / \mathrm{L}$ & 1 & 0.88 & 0.93 & 0.94 & 0.93 \\
\hline 8 & Kalsium & $\mathrm{mg} / \mathrm{L}$ & 200 & 122.15 & 57 & 94 & 54 \\
\hline 9 & Kholida & $\mathrm{mg} / \mathrm{L}$ & 600 & 3.0 & 7.5 & 25 & 19 \\
\hline 10 & Kesadahan & $\mathrm{mg} / \mathrm{L}$ & 500 & 49.55 & 45.88 & 53.84 & 65.11 \\
\hline 11 & Magnesium & $\mathrm{mg} / \mathrm{L}$ & 150 & 4.11 & 18.1 & 21.8 & 17.3 \\
\hline 12 & Mangan & $\mathrm{mg} / \mathrm{L}$ & 0.5 & 0.28 & 9.14 & 12.22 & 1.99 \\
\hline 13 & Nitrat & $\mathrm{mg} / \mathrm{L}$ & 50 & 1.8 & 5.2 & 12.2 & 11.8 \\
\hline 14 & Nitrit & $\mathrm{mg} / \mathrm{L}$ & 3 & 0.24 & 0.14 & 0.009 & 0.18 \\
\hline 15 & Sulfat & $\mathrm{mg} / \mathrm{L}$ & 400 & 7.5 & 149.32 & 121.67 & 35.71 \\
\hline 16 & Zat Padat Terlarut & $\mathrm{mg} / \mathrm{L}$ & 1500 & 621 & 339 & 152 & 152 \\
\hline 17 & Zat Organik & $\mathrm{mg} / \mathrm{L}$ & - & - & 0.3 & 1.1 & 0.2 \\
\hline 18 & Timbal & $\mathrm{mg} / \mathrm{L}$ & 0.05 & 0.02 & 0.02 & 0.03 & 0.002 \\
\hline 19 & Kronium & $\mathrm{mg} / \mathrm{L}$ & 0.05 & - & 0.03 & 0.02 & - \\
\hline & BIOLOGI & & & & & & \\
\hline 20 & Bakteri Coliform & & - & - & - & - & - \\
\hline
\end{tabular}


Tabel 5. Hasil penelitian 5.

\begin{tabular}{|r|l|c|c|c|c|c|c|}
\hline \multirow{2}{*}{ No } & \multirow{2}{*}{ Parameter } & \multirow{2}{*}{ Satuan } & \multirow{2}{*}{$\begin{array}{c}\text { Batas max } \\
\text { air bersih }\end{array}$} & \multicolumn{4}{|c|}{ Hasil Penelitian } \\
\cline { 5 - 8 } & & & & & $\mathrm{Q}$ & $\mathrm{S}$ & $\mathrm{T}$ \\
\hline & FISIKA & & & & & \\
\hline 1 & Warna & $\mathrm{TCU}$ & 50 & 10 & 3 & 5 & 9 \\
\hline 2 & Rasa & - & $\mathrm{x}$ & $\mathrm{x}$ & $\mathrm{x}$ & $\mathrm{X}$ & $\mathrm{X}$ \\
\hline 3 & Bau & - & $\mathrm{x}$ & $\mathrm{x}$ & $\mathrm{x}$ & $\mathrm{x}$ & $\mathrm{X}$ \\
\hline 4 & Kekeruhan & $\mathrm{NTU}$ & 25 & 2.7 & 0 & 0 & 2.9 \\
\hline 5 & Konduktivity & $\mathrm{Ms}$ & - & 298 & 490 & 205 & 512 \\
\hline & KIMIA & & & & & & \\
\hline 6 & pH & $\mathrm{mg} / \mathrm{L}$ & $6.5-9.0$ & 4.48 & 7.33 & 6.65 & 5.24 \\
\hline 7 & Besi & $\mathrm{mg} / \mathrm{L}$ & 1 & 1.38 & 1.03 & 1.04 & 1.03 \\
\hline 8 & Kalsium & $\mathrm{mg} / \mathrm{L}$ & 200 & 22.55 & 128 & 129 & 64 \\
\hline 9 & Kholida & $\mathrm{mg} / \mathrm{L}$ & 600 & 5.8 & 70.7 & 15 & 27 \\
\hline 10 & Kesadahan & $\mathrm{mg} / \mathrm{L}$ & 500 & 19.51 & 76.32 & 63.38 & 19.13 \\
\hline 11 & Magnesium & $\mathrm{mg} / \mathrm{L}$ & 150 & 11.1 & 7.3 & 18.6 & 15.53 \\
\hline 12 & Mangan & $\mathrm{mg} / \mathrm{L}$ & 0.5 & 0.28 & 9.44 & 13.29 & 1.81 \\
\hline 13 & Nitrat & $\mathrm{mg} / \mathrm{L}$ & 50 & 7.29 & 7.27 & 5.47 & 5.15 \\
\hline 14 & Nitrit & $\mathrm{mg} / \mathrm{L}$ & 3 & 0.578 & 0.041 & 0.237 & 0.389 \\
\hline 15 & Sulfat & $\mathrm{mg} / \mathrm{L}$ & 400 & 7.5 & 348.49 & 121.67 & 75.93 \\
\hline 16 & Zat Padat Terlarut & $\mathrm{mg} / \mathrm{L}$ & 1500 & 62 & 734 & 250 & 381 \\
\hline 17 & Zat Organik & $\mathrm{mg} / \mathrm{L}$ & - & 8.1 & 2.3 & 1.9 & 0.2 \\
\hline 18 & Timbal & $\mathrm{mg} / \mathrm{L}$ & 0.05 & 0.02 & 0.67 & 0.18 & 0.001 \\
\hline 19 & Kronium & $\mathrm{mg} / \mathrm{L}$ & 0.05 & 0 & 0.03 & 0.02 & 0 \\
\hline & BIOLOGI & & & & & & \\
\hline 20 & Bakteri Coliform & & - & - & - & - & - \\
\hline
\end{tabular}

Dari ke 20 data sampel air yang diteliti, sampel pada awalnya terlihat berwarna keputihan, secara kasat mata, $\mathrm{pH}$ air masih ada yang berada dibawah netral, berarti air agak asam, dan dari hasil pemeriksaan laboratorium juga terdapat kandungan Mangan, Besi, dan Timbal, serta konduktifitynya cenderung tinggi.

\section{KESIMPULAN}

Perlu diadakan IPAS atau Instalasi Pengolahan Air Sederhana dan belum dapat dikonsumsi baik secara langsung maupun dilakukan pematangan terlebih dahulu, dikarenakan jika dikonsumsi dalam jangka waktu yang cukup lama akan dapat menimbulkan kerusakan pada organ tubuh terutama pada ginjal.

\section{SARAN}

Dikarenakan air permukaan yang terdapat pada lokasi PT.Summit Plast, Cikarang belum memenuhi syarat $^{2}$ akan air bersih, karena masih terdapat bahan bahan ${ }^{2}$ yang membahayakan bagi kesehatan pengguna, maka diperlukan :

1. Pelestarian lingkungan, antara lain dengan penanaman tumbuhan, baik itu tanaman semak maupun tanaman keras. 


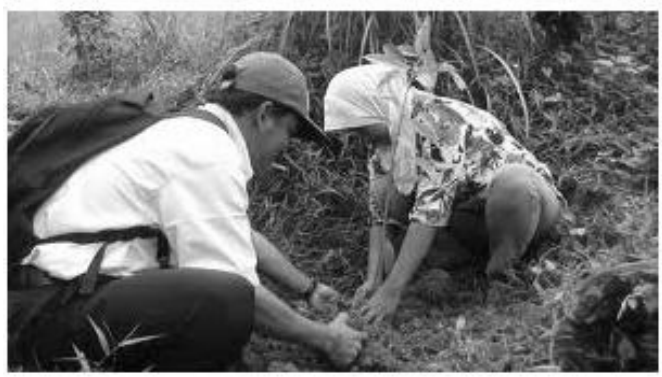

\section{Gambar 4. Pelestarian Lingkungan [http:// Google.com/search/pelestarian} lingkungan]

2. Dapat dilakukannya pengolahan air sederhana.

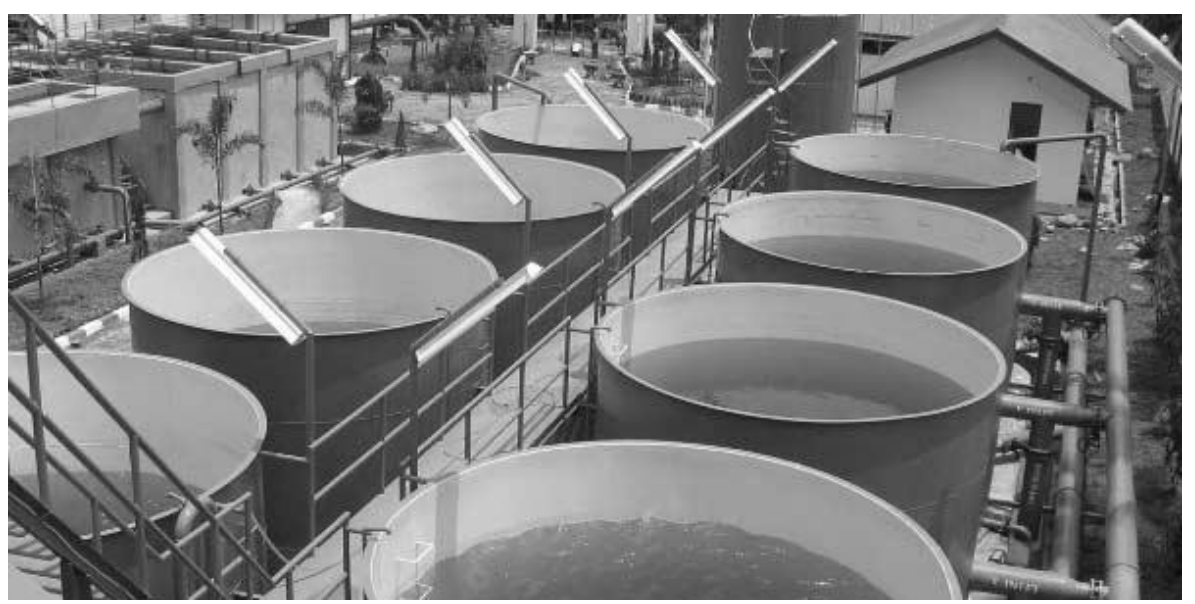

Gambar 5. BUMDes Untuk Pengelolaan Air Bersih Di Desa-Desa [http:// inilahjabar.com]

\section{DAFTAR PUSTAKA}

1. Anwar, Alizar (2004). "Pelayanan Air Minum Wilayah Perkotaan di Indonesia”. Journalist Workshop on Water Issues.

2. Bob Ewing (2008). "Nanotechnology Used to Clean Water". http://www.digitaljournal.com/article/250604/Nanotechnology_Used_to_Clean _Water

3. Fajar Indonesia (26 Maret 2009). "Indonesia Diambang Krisis Air Bersih”. http://www.fajar.co.id/index.php?act=news\&id=58718

4. LeChevallier, Mark W. dan Au, Kwok-Keung (2004). Process Efficiency in Achieving Safe Drinking Water. World Health Organization (WHO).

5. McMahon, James P. "Are you worried about What's in Your Water? You Should Be.”. http://www.cleanairpurewater.com/ 
6. McMullan, Bob (2009). “AusAID: Water Report Highlights Need For Improved Sanitation and Water". M2 Communications Ltd. http://proquest.umi.com/pqdweb?did=1665500131\&sid=1\&Fmt=3\&clientId=67 $249 \& \mathrm{RQT}=309 \& \mathrm{VName}=\mathrm{PQD}$

7. Westjavawater (2005). “Cekungan Bandung Kritis (Bandung Basin Critical)”. http://westjavawater.blogspot.com/2005_03_01_archive.html

8. Westjavawater (2005). "168 Juta Penduduk belum Dapat Akses Air Bersih, Indonesia akan Krisis Air pada 2025 (No Clean Water Access, Water Crisis by 2025)”. http://westjavawater.blogspot.com/2005_03_01_archive.html

9. http://zeofilt.wordpress.com/2008/01/31/sistem-pengolahan-air-bersih/ 